Revista Brasileira de Agricultura Irrigada v.10, nº.4, p. 750 - 757, 2016

ISSN 1982-7679 (On-line)

Fortaleza, CE, INOVAGRI - http://www.inovagri.org.br

DOI: $10.7127 /$ rbai.v10n400396

Protocolo 396.16 - 02/07/2016 Aprovado em 24/08/2016

\title{
EFICIÊNCIA DO USO DA ÁGUA PELO MILHO DOCE EM DIFERENTES LÂMINAS DE IRRIGAÇÃO E ADUBAÇÃO NITROGENADA EM COBERTURA
}

\author{
E. J. Souza ${ }^{1}$, F. F. Cunha², F. F. Magalhães ${ }^{3}$, T. R. Silva ${ }^{4}$, O. F. Santos ${ }^{3}$
}

\begin{abstract}
RESUMO
Objetivou-se avaliar o efeito de diferentes doses de adubação nitrogenada e lâminas de irrigação em duas épocas de cultivo sobre a eficiência do uso da água (EUA) pelo milho doce no nordeste do Mato Grosso do Sul. O experimento foi conduzido em parcelas sub-subdivididas, tendo nas parcelas quatro lâminas de irrigação (50, 75, 100 e 125\% da evapotranspiração da cultura ETc), nas subparcelas quatro doses de nitrogênio em cobertura (0, 100, 200 e $\left.300 \mathrm{~kg} \mathrm{ha}^{-1}\right)$ e nas sub-subparcelas duas épocas de cultivo (Inverno/Primavera e Verão/Outono), no delineamento em blocos casualizados, com quatro repetições. A época Verão/Outono proporcionou maiores eficiências do uso da água para o milho doce no nordeste sul-mato-grossense e o aumento da lâmina de irrigação proporcionou redução desse parâmetro. A adubação nitrogenada aumentou a eficiência do uso da água pelo milho doce na época Verão/Outono e a dose de 168,4 kg ha-1 maximiza esse parâmetro no Inverno/Primavera.
\end{abstract}

Palavras-chave: Irrigação por gotejamento, EUA, Zea mays var. Saccharata Sturt.

\section{WATER USE EFFICIENCY BY SWEET CORN ON DIFFERENT IRRIGATION DEPTH AND TOP-DRESSING WITH NITROGEN}

\begin{abstract}
The aimed was to evaluate the effect of different doses of nitrogen fertilization and irrigation depths in two cropping seasons on water use efficiency of sweet corn in Brazil. The experiment was conducted in of split plot scheme, having in the plots four irrigation depths $(50,75,100$ and $125 \%$ of crop evapotranspiration) and in the subplots, four nitrogen rates $(0,100,200$ and $300 \mathrm{~kg} \mathrm{ha}{ }^{-1}$ ) and in the sub-subplots, two cropping seasons (Winter/ Spring and Summer/Autumn), in the randomized blocks design with four replications. The Summer/Autumn season provides greater water use efficiency for sweet corn in northeastern

\footnotetext{
${ }^{1}$ Doutorando em agronomia, UNESP, Ilha Solteira, SP, Brasil - epitacio.agro@gmail.com.

${ }^{2}$ Doutor em Engenharia Agrícola, Professor Adjunto na UFV, Viçosa, MG, Brasil- fernando.cunha@ufv.br.

${ }^{3}$ Mestrando em agronomia, UFMS, Chapadão do Sul, MS, Brasil- magalhaes.fernandof@gmail.com, thiago.ramossilva10@gmail.com, osvaldir.feliciano@gmail.com.

${ }^{4}$ Graduando em agronomia, UFMS, Chapadão do Sul, MS, Brasil- thiago.ramossilva10@gmail.com
} 
Mato Grosso do Sul state and increased irrigation depth provides reduction of this parameter. Nitrogen fertilization increases the water use efficiency on sweet corn at the Summer/Autumn season and the dose of $168.4 \mathrm{~kg} \mathrm{ha}^{-1}$ maximizes this parameter in the Winter/Spring season.

Keywords: Drip irrigation; WUE; Zea mays var. Saccharata Sturt.

\section{INTRODUÇÃO}

O Brasil se destaca mundialmente como um dos maiores produtores de milho comum, fato que possibilita o País ter também um grande potencial para a produção de milho doce (Zea mays var. Saccharata Sturt) (FERREIRA et al., 2011). A principal diferença entre o milho comum e o milho doce é a composição de seu endosperma, devido aos seus altos teores de açúcares em relação ao amido (KWIATKOWSKI; CLEMENTE, 2007).

A evapotranspiração do milho doce geralmente excede a precipitação pluvial, sendo assim, a distribuição de água de maneira artificial por meio de irrigação é a garantia para se produzir como planejado, sem que a falta de chuvas altere os índices de produtividade e de rentabilidade previamente estabelecidos. A irrigação é considerada a maior usuária de recursos hídricos, e nos últimos tempos observase um aumento da pressão de órgãos públicos sobre os agricultores, para o racionamento e adoção de sistemas mais eficientes de aplicação de água na agricultura, sendo necessário dessa forma melhorar a eficiência de uso da água (CUNHA et al.,2008).

Os benefícios da irrigação são potencializados quando associados a outros manejos, como a nutrição mineral de plantas. No manejo da adubação, o nitrogênio merece destaque especial, pois conforme verificado por Okumura et al. (2013) e Okumura et al. ( 2011), o nitrogênio é o nutriente absorvido em maior quantidade pelo milho doce, o que mais afeta no rendimento e o que possui comportamento mais instável no solo.
As informações relacionadas nutrição mineral do nitrogênio no milho doce são escassas na literatura, em virtude disso a cultura é conduzida tomando como referência as recomendações para o milho comum (CARMO et al., 2012). Práticas de manejo envolvendo adubação nitrogenada e irrigação na produção de milho vem apresentando resultados satisfatórios (DI PAOLO; RINALDI, 2008; XAVIER et al.,2014)

Objetivou-se avaliar o efeito da irrigação e da adubação nitrogenada na eficiência do uso da água pelo milho doce em duas épocas de cultivo no nordeste do Mato Grosso do Sul.

\section{MATERIAL E MÉTODOS}

O experimento foi conduzido na área experimental da Universidade Federal de Mato Grosso do Sul, campus de Chapadão do Sul-MS. O clima é classificado como tropical úmido. A temperatura anual varia entre 13 e $28^{\circ} \mathrm{C}$, a precipitação pluviométrica média anual é de $1.850 \mathrm{~mm}$, com concentração de chuva no verão e seca no inverno (CUNHA et al., 2013).

O solo é classificado como Latossolo Vermelho Amarelo Distrófico, textura argilosa, com massa específica de $1,21 \mathrm{~g} \mathrm{~cm}^{-3}$ e teores de água equivalente à capacidade de campo e ponto de murcha permanente da planta de 0,2632 e $0,1887 \mathrm{dm}^{3} \mathrm{dm}^{-3}$, respectivamente. Os atributos químicos do solo foram determinados antes de cada cultivo e realizados no Laboratório Inside de Chapadão do Sul-MS (Tabela 1).

Tabela 1. Resultados da análise química do solo da área experimental em diferentes épocas de cultivo. Chapadão do Sul - MS, Brasil, 2012-2013.

\begin{tabular}{|c|c|c|c|c|c|c|c|c|c|c|}
\hline Época & $\begin{array}{c}\text { Camada } \\
(\mathrm{cm})\end{array}$ & $\begin{array}{c}\mathrm{pH} \\
\mathrm{CaCl}_{2}\end{array}$ & $\mathrm{Ca}+\mathrm{Mg}$ & \multicolumn{4}{|c|}{$\mathrm{cmol}_{\mathrm{C}} \mathrm{dm}^{-3}$} & K & $\mathrm{mg} \mathrm{dm} \mathrm{dm}^{-3}$ & $\begin{array}{l}\mathrm{P}(\mathrm{mel}) \\
\mathrm{Im}^{-3}\end{array}$ \\
\hline & $0-20$ & 5,3 & 4,20 & 3,30 & 0,90 & 0,08 & 4,9 & 0,29 & 113 & 13,8 \\
\hline Inv/Prl & $20-40$ & 5,1 & 2,40 & 1,90 & 0,50 & 0,24 & 5,0 & 0,12 & 47 & 4,8 \\
\hline
\end{tabular}


EFICIÊNCIA DO USO DA ÁGUA PELO MILHO DOCE EM DIFERENTES LÂMINAS DE IRRIGAÇÃO E ADUBAÇÃO NITROGENADA EM COBERTURA

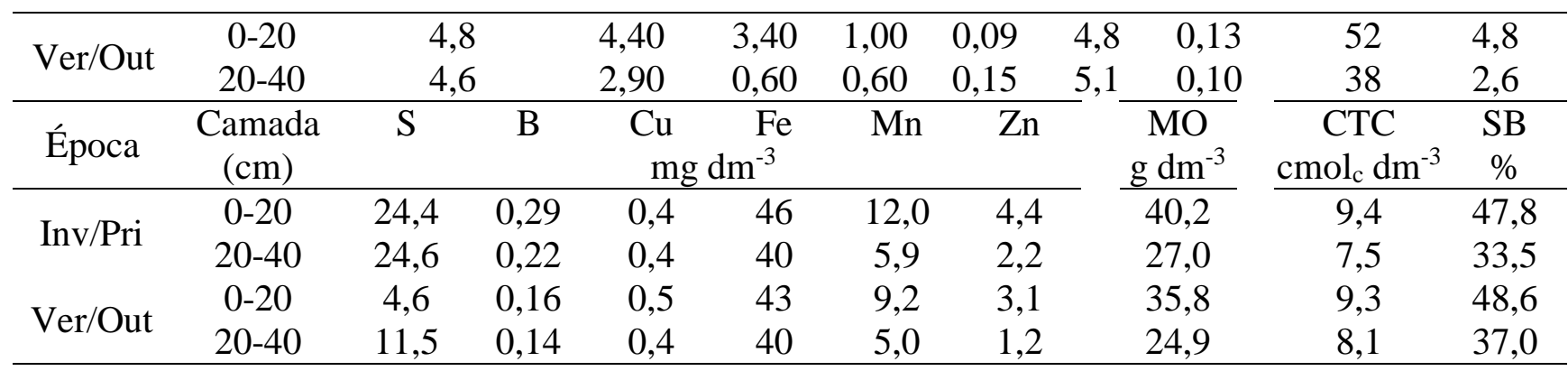

M.O. = Matéria orgânica; SB = Saturação de Bases; CTC= Capacidade de Troca Catiônica.

O experimento foi conduzido em parcelas sub-subdivididas, tendo nas parcelas quatro lâminas de irrigação (50, 75, 100 e 125\% da evapotranspiração da cultura - ETc), nas subparcelas quatro doses de nitrogênio $(0,100$, 200 e $300 \mathrm{~kg} \mathrm{ha}^{-1}$ ) e nas sub-subparcelas duas épocas de cultivo (Inverno/Primavera entre 17/8/2012 e 24/11/2012 e Verão/Outono entre 2/3/2013 e 31/05/2013), no delineamento em blocos casualizados, com quatro repetições.

As unidades experimentais foram constituídas de parcelas com 2,5 m de comprimento (bordadura de 0,5 m) e 4,8 $\mathrm{m}$ de largura (bordadura de $0,8 \mathrm{~m}$ ), resultando em uma área total de $12 \mathrm{~m}^{2}$ e útil de 4,8 $\mathrm{m}^{2}$.

As semeaduras foram realizadas nos dias 17/8/2012 (Inverno/Primavera) e 2/3/2013 (Verão/Outono), com o espaçamento de $80 \mathrm{~cm}$ entre fileiras, adotando uma densidade de 75.000 sementes ha $^{-1}$. Foi utilizado o híbrido simples Tropical Plus ${ }^{\circledR}$, da empresa Syngenta.

A adubação nitrogenada de cobertura foi dividida e aplicada nas fases fenológicas V3(três folhas desenvolvidas) e V8(oitos folhas desenvolvidas ). A uréia foi aplicada na fileira de plantas, junto às fitas gotejadoras, que foram acionadas após a adubação para minimizar as perdas por volatização. Na fase fenológica estádio V3, também foi realizada a adubação potássica de cobertura com $80 \mathrm{~kg} \mathrm{ha}^{-1}$ de $\mathrm{K}_{2} \mathrm{O}$.

Utilizou-se o sistema de irrigação por gotejamento, por meio de fita gotejadora (mangueira gotejadora Petroisa). Os emissores (gotejadores) operaram com pressão de serviço de $98 \mathrm{kPa}$ aplicando vazão aproximada de 1,1 L $\mathrm{h}^{-1}$, e espaçados de $20 \mathrm{~cm}$ tendo uma fita para cada fileira de planta. A Equação 1 foi utilizada para cálculo da irrigação real necessária para o tratamento de $100 \%$ da ETc.

$$
\mathrm{IRN}_{\mathrm{LOC}}=\sum_{\text {dia } 1}^{\mathrm{i}} \mathrm{ET}_{0} \mathrm{~K}_{\mathrm{C}} \mathrm{K}_{\mathrm{S}} \mathrm{K}_{\mathrm{L}}-\mathrm{P}_{\mathrm{E}}
$$

em que: IRN $N_{L O C}$ é a irrigação real necessária em sistemas localizados (mm); $\mathrm{ET}_{0}$ a evapotranspiração de referência (mm dia $\left.{ }^{-1}\right)$; $\mathrm{K}_{\mathrm{C}}$ o coeficiente da cultura (adimensional); $\mathrm{K}_{\mathrm{S}} \mathrm{O}$ coeficiente de umidade do solo (adimensional); $\mathrm{K}_{\mathrm{L}}$ o coeficiente de localização (adimensional); e $\mathrm{P}_{\mathrm{E}}$ a precipitação efetiva no período ( $\mathrm{mm}$ ).

A metodologia de Penman-Monteith foi utilizada para o cálculo da evapotranspiração de referência $\left(\mathrm{ET}_{0}\right)$. Os coeficientes de cultivo $(\mathrm{Kc})$, adaptado de Doorenbos e Pruitt (1979), foram de 0,7 e 1,1 para os estádios I e III, respectivamente. Para o estádio II utilizou-se ponderação linear entre o final do estádio I e início do estádio IIII. A duração dos estádios I e II foram de 20 e 30 dias, respectivamente, e o estádio III deu início a partir do quinquagésimo dia estendendo até a colheita. Os coeficientes de umidade do solo, de localização e precipitação efetiva foram obtidos de acordo com Bernardo et al. (2008).

Ao atingirem a fase fenológica R3(grão leitoso), foram realizadas a colheita das espigas. As colheitas foram realizadas em 24/11/2012 e 31/5/2013 para as épocas de cultivo Inverno/Primavera e Verão/Outono, respectivamente. A eficiência de uso da água foi determinada pela razão entre a produtividade de espiga de milho doce e a quantidade de água utilizada em cada tratamento (Equação 1), seguindo recomendações de Pieterse et al. (1997).

$$
\mathrm{EUA}=\frac{\mathrm{P}}{\mathrm{L}}
$$

Em que: EUA = eficiência do uso da água $\left(\mathrm{kg} \mathrm{m}^{-3}\right) ; \mathrm{P}=$ produtividade do milho doce $(\mathrm{kg}$ 
ha-1); e L = lâmina de água utilizada no período de produção $\left(\mathrm{m}^{3} \mathrm{ha}^{-1}\right)$.

Os dados foram submetidos às análises de variância e regressão. Utilizou-se o teste de Tukey, a 5\% de probabilidade, para comparação de médias. Para os fatores quantitativos, testouse os modelos lineares e quadráticos. A seleção

\section{RESULTADOS E DISCUSSÃO}

As variações dos elementos meteorológicos diários nos dois períodos de

A.

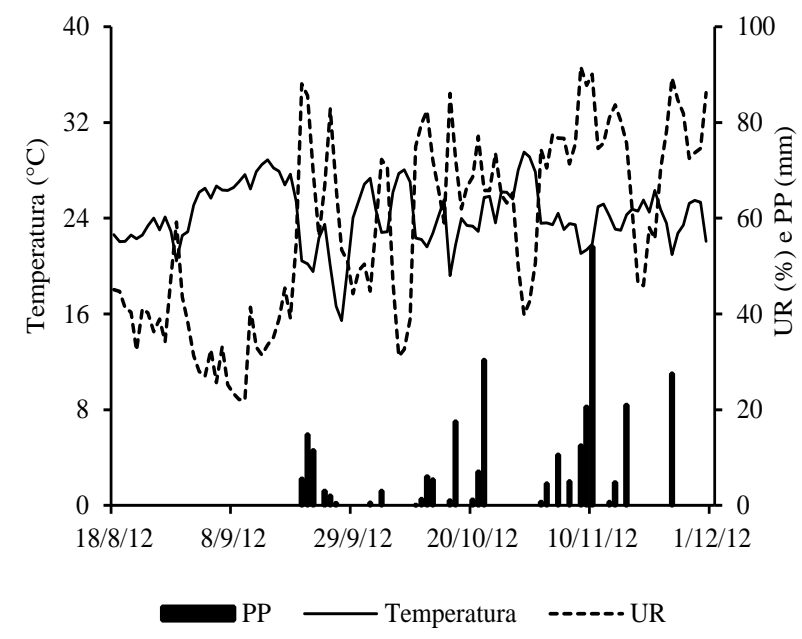

do modelo foi com base na significância dos coeficientes de regressão, utilizando-se o teste $t$ a 5\% de probabilidade, no coeficiente de determinação $\left(\mathrm{R}^{2}\right)$ e no fenômeno biológico. Utilizaram-se os programas "Assistat 7.6" e "Sigmaplot 11.0” para realização das análises estatísticas.

cultivo do milho doce estão apresentadas nas Figuras 1.

B.

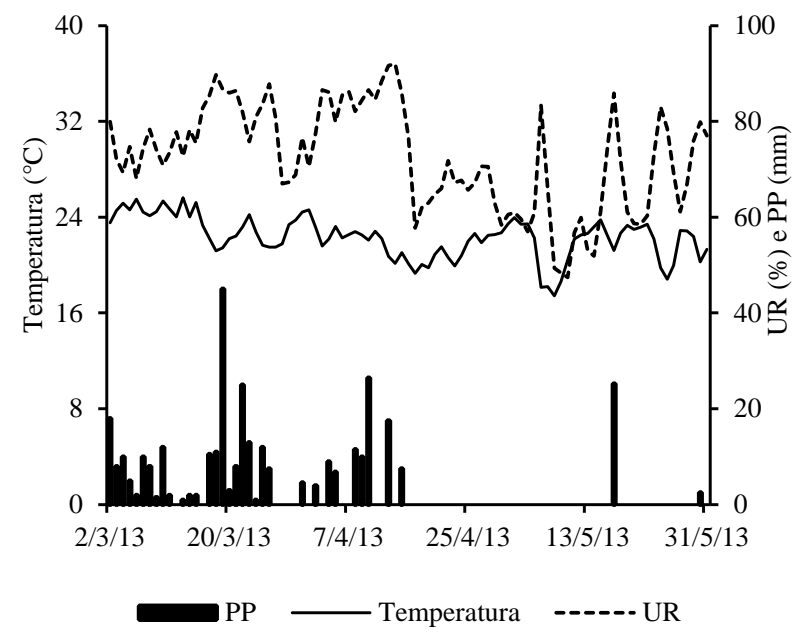

Figura 1. Variação diária da temperatura do ar $\left({ }^{\circ} \mathrm{C}\right)$, umidade relativa do ar- UR (\%) e precipitação pluvial- PP (mm), nas épocas de cultivo: (A) Inverno/Primavera e (B) Verão/Outono. Chapadão do Sul - MS, 2012-2013.

A temperatura média diária do ar foi maior na primeira época de cultivo (Inverno/Primavera), alcançando um valor médio de $24,2{ }^{\circ} \mathrm{C}$, variando dentro de uma amplitude de 15,4 a $29,5^{\circ} \mathrm{C}$. Na segunda época de cultivo (Verão/Outono), o valor médio foi de $22,3{ }^{\circ} \mathrm{C}$, oscilando entre 17,4 e $25,6{ }^{\circ} \mathrm{C}$.

A $\mathrm{ET}_{0}$ também foi maior no período de cultivo que abrangeu o Inverno/Primavera, alcançando um valor médio de $4,3 \mathrm{~mm} \mathrm{dia}^{-1}$, variando dentro de uma amplitude de 1,5 a 6,5 $\mathrm{mm} \mathrm{dia}^{-1}$. No período Verão/Outono, o valor médio foi de 3,2 $\mathrm{mm} \mathrm{dia}^{-1}$, oscilando entre $1,8 \mathrm{e}$ $5,3 \mathrm{~mm} \mathrm{dia}^{-1}$.

No período Inverno/Primavera, as precipitações pluviais concentraram no final do ciclo do milho doce somando uma altura de 270,3 mm, distribuídos em 23 eventos, com alturas variando de 2,6 a 54,0 mm. Ertek e Kara,
(2013), estudando lâminas de irrigação em milho doce em duas épocas de cultivo na Turquia, verificou situação semelhante em relação as condições climáticas. Estes autores explicam que a variação da evapotranspiração foi maior de uma época em relação a outra devido à maior precipitação, as altas temperaturas, e a baixa humidade relativa do ar. Deste modo, a proporção de vapor de água no ar diminuiu e a perda de água por evaporação é aumentada.

Obteve-se maior precipitação efetiva no milho doce cultivado na época Inverno/Primavera (Tabela 2). Esse resultado é devido às precipitações pluviais terem se concentrado em períodos que a cultura apresentava maiores valores de coeficiente de cultivo $\left(K_{C}\right)$ e de localização $\left(K_{L}\right)$, e diante disso, maior demanda evapotranspirométrica. 


\section{EFICIÊNCIA DO USO DA ÁGUA PELO MILHO DOCE EM DIFERENTES LÂMINAS DE IRRIGAÇÃO E ADUBAÇÃO NITROGENADA EM COBERTURA}

Tabela 2. Precipitação efetiva, irrigação real necessária e lâmina de água total aplicada em cada tratamento e época de cultivo. Chapadão do Sul-MS, UFMS-CPCS, 2012-2013

\begin{tabular}{clcccc}
\hline \multirow{2}{*}{ Época } & \multicolumn{2}{c}{ Evento } & \multicolumn{3}{c}{ Lâminas de Irrigação } \\
\cline { 3 - 6 } & & $50 \%$ ETc & $75 \%$ ETc & $100 \%$ ETc & $125 \%$ ETc \\
\hline \multirow{2}{*}{ Inverno/ } & Precipitação Efetiva (mm) & 258,8 & 220,6 & 185,1 & 185,1 \\
Primavera & Irrigação Real Necessária (mm) & 111,3 & 167,0 & 222,7 & 278,4 \\
& Lâmina de Água Total (mm) & 370,1 & 387,7 & 407,8 & 463,4 \\
\hline \multirow{2}{*}{ Verão/ } & Precipitação Efetiva (mm) & 213,7 & 208,6 & 196,2 & 196,2 \\
\multirow{2}{*}{ Outono } & Irrigação Real Necessária (mm) & 64,5 & 96,8 & 129,1 & 161,3 \\
& Lâmina de Água Total (mm) & 278,3 & 305,4 & 325,3 & 357,6 \\
\hline
\end{tabular}

Houve maior consumo de água pelo milho doce cultivado na época Inverno/Primavera (Tabela 2). Esse resultado foi alcançado devido a dois motivos principais, maior demanda evapotranspirométrica ocasionadas pelas maiores temperaturas e menores umidades relativas do ar; e maior ciclo da cultura nesse período. No cultivo conduzido no Inverno/Primavera o ciclo da cultura foi de 99 dias, enquanto que no Verão/Outono de 90 dias.

De acordo com a análise de variância, houve interação entre épocas de cultivo e lâminas de irrigação na eficiência do uso da água (EUA) pelo milho doce (Tabela 3).

Tabela 3. Análises de variância de produtividade de espigas (PE) e eficiência do uso da água (EUA)

\begin{tabular}{lcl}
\hline FV & GL & EUA \\
\hline Bloco & 3 & $5,95 \mathrm{E}+0^{\mathrm{ns}}$ \\
LI & 3 & $1,91 \mathrm{E}+1^{* *}$ \\
Resíduo (A) & 9 & $1,69 \mathrm{E}+0$ \\
DN & 3 & $2,08 \mathrm{E}+0^{*}$ \\
LI x DN & 9 & $4,68 \mathrm{E}-1^{\text {ns }}$ \\
Resíduo (B) & 36 & $7,11 \mathrm{E}-1$ \\
EC & 1 & $7,87 \mathrm{E}+1^{* *}$ \\
LI x EC & 3 & $1,01 \mathrm{E}+1^{* *}$ \\
DN x EC & 3 & $1,10 \mathrm{E}+0^{\mathrm{ns}}$ \\
LI x DN x EC & 9 & $5,66 \mathrm{E}-1^{\mathrm{ns}}$ \\
Resíduo (C) & 48 & $8,83 \mathrm{E}-1$ \\
\hline CV (\%) Parcela & & 26,72 \\
CV (\%) Sub-parcela & 17,31 \\
CV (\%) Sub-subparcela & 19,28 \\
\hline
\end{tabular}

Na lâmina de irrigação de $125 \%$ da ETc, não foi verificado diferença; e nas demais lâminas, verificou-se maiores EUA na época Verão/Outono (Tabela 4). Esse resultado foi devido a dois motivos ocorridos: (a) menores lâminas totais de água recebida (Tabela 2); e (b) maiores produtividades de espiga de milho doce. Analisando o valor médio de EUA, que foi de $4,87 \mathrm{~kg} \mathrm{~m}^{-3}$, pode-se afirmar que para produção de $1 \mathrm{~kg}$ de espiga de milho doce, são necessários 205 litros de água.

Tabela 4. Valores médios de eficiência do uso da água (EUA) nas épocas Inverno/Primavera e Verão/Outono. Chapadão do Sul - MS, UFMS-CPCS, 2012-2013

\begin{tabular}{ccccccc}
\hline \multirow{2}{*}{ Parâmetro } & \multirow{2}{*}{ Época } & \multicolumn{4}{c}{ Lâminas de Irrigação } \\
\cline { 4 - 7 } & & & $50 \%$ ETc & $75 \%$ ETc & $100 \%$ ETc & $125 \%$ ETc \\
\hline EUA & Inverno/Primavera & \multirow{2}{*}{0,67} & $4,56 \mathrm{~b}$ & $3,76 \mathrm{~b}$ & $4,30 \mathrm{~b}$ & $3,73 \mathrm{a}$ \\
$\left(\mathrm{kg} \mathrm{m}^{-3}\right)$ & Verão/Outono & & $7,04 \mathrm{a}$ & $6,34 \mathrm{a}$ & $5,10 \mathrm{a}$ & $4,15 \mathrm{a}$ \\
\hline
\end{tabular}


dms = diferença mínima significativa; Médias seguidas de mesma letra nas colunas não diferem entre si pelo teste de Tukey $(p<0,05)$.

Verificou-se redução da EUA com o aumento da lâmina de irrigação devido a esses fatores serem inversamente proporcionais (Figura 2). Na época Verão/Outono, a redução da EUA em função da lâmina de irrigação foi maior devido a uma menor produtividade de espigas ocorrida nessa época de cultivo. Este efeito linear negativo das lâminas de irrigação na EUA também foi observado por Garcia et al. (2009) trabalhando

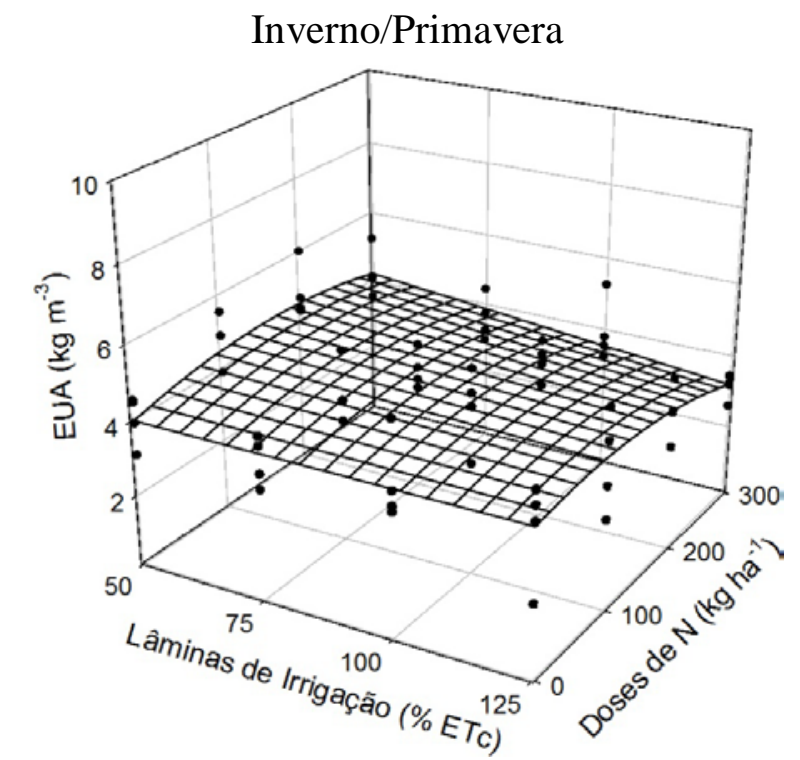

$$
\begin{gathered}
\mathrm{EUA}=4,0 \mathrm{E}+0^{* *}+9,4 \mathrm{E}-3^{*} \mathrm{DN}-4,6 \mathrm{E}-5^{*} \mathrm{LI} \mathrm{DN}-2,1 \mathrm{E}-5^{*} \mathrm{DN}^{2} \\
\mathrm{R}^{2}=0,4993 \quad p<0,0196
\end{gathered}
$$$$
* p<0,05 ; * * p<0,01
$$

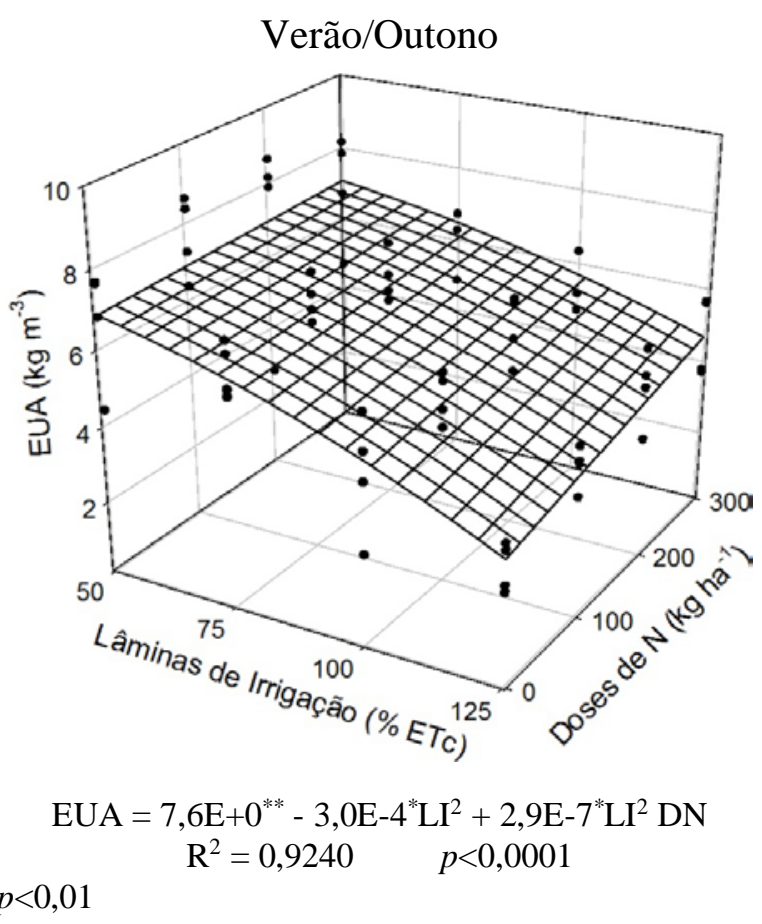

$$
\begin{gathered}
\mathrm{EUA}=7,6 \mathrm{E}+0^{* *}-3,0 \mathrm{E}-4^{*} \mathrm{LI}^{2}+2,9 \mathrm{E}-7^{*} \mathrm{LI}^{2} \mathrm{DN} \\
\mathrm{R}^{2}=0,9240 \quad p<0,0001
\end{gathered}
$$

em Pombal-PB Brasil. Na época Inverno/Primavera a adubação nitrogenada proporcionou efeito quadrático na EUA do milho doce, sendo $168,4 \mathrm{~kg} \mathrm{ha}^{-1}$ de $\mathrm{N}$ a dose que maximizou esse parâmetro, de acordo com a equação de regressão (Figura 1). As doses de nitrogênio na época Verão/Outono apresentaram efeito linear positivo.

Figura 2. Estimativa da eficiência do uso da água (EUA) em função das lâminas de irrigação (LI) e doses nitrogenadas (DN) nas diferentes épocas de cultivo. Chapadão do Sul - MS, UFMS-CPCS, 2012-2013.

Segundo Ertek e Kara, (2013), se a lâmina de agua aplicada for ligeiramente abaixo da capacidade de campo, isso afetaria a aeração do solo e o desenvolvimento radicular seria melhor, além disso nesta condição o processo de lixiviação de nutrientes é reduzido. Diante desta afirmação, sugere o efeito das doses de nitrogênio foi suprimido na época cultivo Inverno/Primavera, pois os eventos pluviométricos neste período se intensificaram após a adubação de nitrogenada de cobertura, indicando poder ter ocorrido perda de nitrogênio por lixiviação.

\section{CONCLUSÕES}

A época Verão/Outono proporciona maiores eficiências do uso da água para milho doce no nordeste de Mato Grosso do Sul.

O aumento da lâmina de irrigação proporciona redução na eficiência do uso da água pelo milho doce.

A adubação nitrogenada aumenta a eficiência do uso da água pelo milho doce na época Verão/Outono e a dose de 168,4 kg ha-1 maximiza esse parâmetro no Inverno/Primavera.

\section{AGRADECIMENTOS}


À CAPES pela concessão de bolsa de estudo, Syngenta Seeds LTDA pela doação das sementes e ao Grupo Feltre pela doação das cápsulas tensiométricas.

\section{REFERÊNCIAS BIBLIOGRÁFICAS}

BERNARDO, S.; SOARES, A.A.; MANTOVANI, E.C. Manual de irrigação. 8.ed. Viçosa: UFV, 2008. 625p.

BRITO, M.E.B.; ARAÚJO FILHO, G.D.; WANDERLEY, J.A.C.; MELO, A.S.; COSTA, F.B.; FERREIRA, M.G.P. Crescimento, fisiologia e produção do milho doce sob estresse hídrico. Bioscience Journal, v.29, n.5, p.12441253, 2013.

CARMO, M. S.; CRUZ, S. C. S.; SOUZA, E. J.; CAMPOS, L. F. C.; MACHADO, C. G. Doses e fontes de nitrogênio no desenvolvimento e produtividade da cultura de milho doce (Zea mays convar. saccharata var. rugosa). Bioscience Journal, v. 28, sup. 1, p. 223-231, 2012.

CUNHA, F.F.; MAGALHÃES, F.F.; CASTRO, M.A. Métodos para estimativa da evapotranspiração de referência para Chapadão do Sul, MS. Engenharia na Agricultura, v.21, n.2, p.159-172, 2013.

CUNHA, F.F.; SOARES, A. A.; SEDIYAMA, G. C.; MANTOVANI, E. C.; PEREIRA, O. G. Efeito de diferentes níveis de irrigação e turnos de rega na eficiência de uso da água pelo capim-tanzânia. Engenharia na Agricultura, v.16, n.4, 449-457, 2008.

DI PAOLO, E.; RINALDI, M. Yield response of corn to irrigation and nitrogen fertilization in a Mediterranean environment. Field Crops Research, v. 105, n. 3, p. 202-210, 2008.

DOORENBOS, J.; PRUITT, W. O. Guidelines for predicting crop water requirements, irrigation and drainage. Rome: FAO, 1975. 179 p. (Irrigation and Drainage Paper. n. 24).
ERTEK, A.; KARA, B. Yield and quality of sweet corn under deficit irrigation. Agricultural water management, v. 129, p. 138-144, 2013

FERREIRA, M.G.; BRITO, M.E.; COSTA, F.B.D.; ARAÚJO FILHO, G.D.D.; ALVINO, F.C. Aspectos químicos e físicos dos grãos de milho doce sob estresse hídrico. Revista Brasileira de Agrotecnologia, v.1, n.1, p.1-6, 2011.

GARCIA, G.A.; GUERRA, L.C.; HOOGENBOOM, G. Water use and water use efficiency of sweet corn under different weather conditions and soil moisture regimes. Agricultural Water Management, v.96, n.10, p.1369-1376, 2009.

KWIATKOWSKI, A; CLEMENTE, E. Características do milho doce (Zea mays L.) para industrialização. Revista Brasileira Agroindustrial, v.1, n.2, p.93-103, 2007.

OKUMURA, R.S.; MARIANO, D.C.; ZACCHEO, P.V.C. Uso de fertilizante nitrogenado na cultura do milho: uma revisão. Revista Brasileira de Tecnologia Aplicada nas Ciências Agrárias, v.4, n.2, p.226-244, 2011.

OKUMURA, R. S.; MARIANO, D. D. C.; FRANCO, A. A. N.; ZACCHEO, P. V. C.; ZORZENONI, T. O. Sweet corn: Genetic aspects, agronomic and nutritional traits. Revista Brasileira de Tecnologia Aplicada nas Ciências Agrárias, v. 6, n. 1, p. 105-114, 2013.

PIETERSE, P. A.; RETHMAN, N. F. G.; VAN $\mathrm{BOCH}$, J. Production, water use efficiency and quality of four cultivars of Panicum maximum Jacq. at different levels of nitrogen fertilization. Tropical Grassland, Brisbane, v. 31, n. 2, p. 117-123, 1997.

XAVIER, D. A.; FURTADO, G. F.; SOUSA JÚNIOR, J.R.; SOUSA, J. R. R.; ANDRADE, E. M. G. Produção de fitomassa do milho sob 
Souza et al.

lâminas de irrigação e adubação nitrogenada. Revista Verde de Agroecologia e
Desenvolvimento Sustentável, v. 9, n. 3, p. 144-148, 2014. 